\title{
Strategies to Change Beliefs that Cause Low Self-Esteem, Depression and Anxiety among Women of Pakistan
}

\author{
Mona Aeysha Khalid \\ Kinnaird College for Women, University, Pakistan \\ Email:mei3na4@gmail.com
}

\section{Doi:10.5901/jesr.2015.v5n2p153}

\section{Abstract}

This paper is designed to investigate the real mind-set behind in-human and unjustifiable beliefs that common people blindly own, accept, belong, respect and name them as traditions. Such beliefs basically are the product of poor economical and weak geographical structure of a society. People who cannot solve their practical problems through scientific research, analytical approaches, and implementation of research based laws; usually dig upon irrational and fatal traditions, beliefs and customs. Their beliefs are not subject to approval; however they consider them as a source of a relief, excuse, justification and means to their identity. In this paper, belief structure, along with historical and philosophical perspective will be addressed to draw a line between the evil and ethical customs of a society. In the end, measures to improve such hypocritical and susceptive belief systems (including traditions, customs, and values) have been discovered, introduced and proposed for future trends.

\section{Objectives}

There are certain psychological beliefs that cause discrimination, injustice and inequality among women of Pakistan. This study would explore the structure of such beliefs with respect to its implication and side effects. The main objectives of the study are:

a. How can we define beliefs and concepts with respect to our unique psychological mind-set?

b. Through how many ways, beliefs (traditional in nature) could play a vital role in our domestic life?

c. What are the strategies to change or alter the beliefs that cause depression, segregation and a continuous anxiety for the women of Pakistan?

\section{Methodology}

In this research work, the observation of subjects ( a small sample of 50 women) for a longer period (approximately 15 to 20 years) was considered being the best approach due to ethical and safety concerns. Though there are other factors being considered due to being as fair (unbiased) as possible in our results, such as medical records, family history, occupational background, genetic information, age and educational standards of families observed.

\section{Sample}

Our sample was consisted of 50 women, house wives, from a middle class family, married, mothers of children ( from one to five years old), with good educational background and with good general physical health. Almost all of them had been diagnosed a patient of depression, anxiety, stress, and emotional hormonal imbalance. Keeping in view the nature of research work and the religious mind set of general public, the real purpose of study was not revealed to the subjects and kept totally confidential.

\section{Introduction}

Women, in Pakistan, are suffering from health issues, domestic violence, physical and emotional abuses, and are victim of many cruel and life threatening customs and traditions. Studies about discrimination against women of Pakistan have shown a 13 percent increase in the domestic violence, rape, karo kari, forced marriages, and related issues in the year 2009 (retrieved from http://www.pakistaniwomen.org/). 
In this study, we will explore the concepts/beliefs that are largely responsible for the women's depression, anxiety and stress overall in day to day life. Among many negative beliefs, the three main ones are: rukhsati, divorce right and property right. These three elements collectively shape a woman's mind a prisoner in the house of her own parents. There are many other concepts in the culture of Pakistan, that need our attention for the same purpose; however we will not discuss them in this paper for being out of scope of this study; and due to the clarity of the concept and having focus on identification of the coping strategies in particular.

At first, a newly born baby girl, is not welcome to this world by her own parents. Her parents accept her unwillingly and unhappily due to her social status in society. She faces discrimination at home, in school, and in the society at large in almost every field of life. Her marriage is mostly decided by her parents and she is supposed to accept it by her heart and soul. After marriage, her home is replaced by her husband's home where she should prove herself an obedient wife and a serving daughter-in-law. She is never welcome back to her parent's home even in case of facing abuse, neglect, tortures, violence or injustice of any kind. She is almost forced to bear it all to save her marriage at any cost. After children, things become more complicated and critical. Mostly, brothers think that they have the right to live in their parent's home forever, being eligible of owning the double property than their sisters. And most sisters think that their share of property is already given to them in the form of dowry. Thus the property right greatly dictates a series of discriminated acts among siblings leading to adverse physical and psychological health effects for the women of Pakistan.

When we start defining different roles for women and men, based on gender only; we are unconsciously paving the way for the sheer amount of discriminated acts in our society. Beliefs that dictate women to do something specific according to the gender role are very common and accepted in great number in Pakistan. People not only strictly observe them, rather in some matters give them supreme priority in their entire life. People at some places would prefer committing suicide instead of facing a women's argument about her own freedom, identity, and view point. Women on the other hand, feel a great amount of stress and anxiety due to such illogical, fake and discriminated rules and beliefs prevailing in the society. Though there is no valid reason to believe in such traditions that generate stress among women; however they rarely dare to confront them with logic, confidence and courage mainly due to lack of power, shelter, money, education and safety.

This paper is not intended to going into the details of discriminated acts, abuses, stresses, psychological disorders among below averaged women, types of anxieties faced by the average women, and any other physical or emotional set back due to patriarchal rules of the society; rather we would high light the strategies on how to deal with such brain washing statements, non reliable beliefs and fake honor preservatives. It is also hypothesized that the rules to change ones mind-set, would prove a mile stone in the field of cognitive research and would introduce a theory to future researchers to verify it with data collection and experimental thorough analysis.

\section{Literature Review}

In this paper the words such as beliefs, traditions, values, and customs are being used interchangeably often due to a subtle and acute nature of difference between these constructs. However, it would be a wise decision to study these schemas in detail before carrying out a critical analysis of their misuse and over use in certain circumstances. Given that every thing has two sides: good and bad, negative and positive, optimistic and pessimistic and right or wrong. Similarly, beliefs by nature are not either right or wrong rather the use we make out of them would define their credibility and true nature. Thus, it is very important to know how we interpret them in our day to day lives through actions, attitudes, gestures and behaviors overall, before reaching any final conclusion.

"Belief is defined in Webster's Unabridged Third New International Dictionary as a 'conviction of the truth of some statement or the reality of some being or phenomenon' (Merriam-Webster, 2000)." (Walters, 2002, p. 21). To understand the true nature of traditional beliefs, we should not ignore the core beliefs deep rooted in our culture, being a prerequisite in the expression of traditions locally or world wide. According to Sim \& Stephen (2011), tradition is a vital and dynamic feature of a culture, a learnt belief that helps to shape and confirms the identity of a person and of community. Traditions reinforce the values and beliefs of the groups. Mostly community members share the same values and beliefs within groups of their interests. For the tradition to pass on to other generations, it is noticed that it does not need to be repeated in exactly the same manner or shared the same lore rather it should only be relevant and meaningful to the group it belongs to. Sim \& Stephens (2011) also noted that "Traditions are those informally shared behaviors, customs, and verbal expressions that circulate within and among groups." (p. 76). To him, folklore possesses both dynamic and conservative features- the formal one is changing and the later one is static in nature. These two features make us 
adaptable as well as capable of preserving a sense of continuity (Sims \& Stephens, 2011, p. 81). Furthermore traditions not only are maintained consistently and persistently by the groups of a society rather may perhaps even be invented within a group as a way to convey and express beliefs to other members of the group or other groups (Sims \& Stephens, 2011, p. 69).

Values in the ethical science, are always expressed with respect to two polar dichotomies: right or wrong; good or bad; the positive or negative ; the beautiful or ugly and valid or not valid (Gross, 1985,p.12). There is no such thing as objective reality that can prove the real nature of values, just the separate realities of individual persons (Walters, 2002,p.44). Therefore, it is practically very difficult to verify them in either direction. Hence, in some regions of this world, values need to be revised, reordered, and renewed for the survival of humanity, for the sake of saving humans from depression, anxiety and low self-esteem. As defined by Halstead \& Reiss (2003), "values are principles and fundamental convictions which act as general guides to behavior, enduring beliefs about what is worthwhile; ideals for which one strives; broad standards by which particular beliefs and actions are judged to be good, right, desirable or worthy of respect. Examples of values are love, fairness, equality, freedom, justice, happiness, security, peace of mind, truth". (P. 5). Raths et al (1966) emphasized on the values being beliefs, attitudes or feelings that an individual is proud of and is willing to publicly affirm ( Halstead \& Reiss, 2003, p. 5).

Whether values are personal, or universal; they become part of a particular culture or tradition within a culture. Thus we can say that beliefs about values of a culture collectively shape traditions, customs and rituals. On the whole, people willingly and unconsciously not only accept those traditions rather feel very much proud of them and promote them through various ways. However, among such traditions based on certain beliefs, some are not right, good or valid from a scientific point of view. In this paper, we will explore some of those traditions ( prominent in the Pakistani culture) in the light of right or wrong and will suggest strategies to eradicate, replace or ignore those beliefs personally and collectively.

\section{Pakistani Domestic Beliefs}

Keeping in view the basic structure of family of Pakistan with respect to traditions, customs, values and norms, the beliefs (negative in nature) that are most commonly adopted, recognized, identified, and practiced at a large level are :

1. Rukhsati

2. Divorce Rights

3. Property Rights

\section{1 'Rukhsati'}

The 'rukhsati' is one of those beliefs that generates discrimination against the women of Pakistan. According to this custom, girls are thought as guest in their parent's home. Parents remind them of their short term stay from time to time directly or indirectly. The future groom's house is usually assumed as girls' real house where they are supposed to live forever. Therefore, since childhood, girls are mentally prepared to live in that house through various reminders like:

"Do not study so hard, it is of no use to you, after all you have to cook food for your husband in your married life"

"Try to learn some cooking, cleaning and serving as you will have to do it all, in your in-laws house"

"Do not love your parents so much, as you will have to leave them one day for your future husband" and so on.

Usually girls internalize all of such messages so strongly that they feel it is the best solution to their problems. They unconsciously involve their selves to preparing for their future life ( with husband and in-laws). They start living in fool's paradise while dreaming, visualizing and imagining the coming unreal life that would be destined to them in the form of their marriage designed/arranged by their parents. Unfortunately, such arranged marriages could not fulfill the criteria of a happy domestic life and result in shocking domestic abuse and alarming violence against women.

\subsection{Divorce Right}

Second important concept is divorce in a domestic life, after marriage. When it comes to divorce in a Pakistani culture, it is again taken as a stigma for girls. Groom can give divorce verbally by saying 'divorce' three times to his wife and that is a legally approved way of giving divorce. Whereas bride has to go to court and file for the divorce, while following the legal formalities in each level. For a girl, it is never appreciated and encouraged even if she is being physically abused or tortured brutally on daily basis. Things are not very simple for girls as they are for boys. Therefore most of the boys use 
their right as a threat against their women in case of not using it practically. Girls, their level best, try to surrender their will, sacrifice their interests and adjust their selves in their husbands home as they would never like to get the label 'divorce' in the Pakistani male dominated, patriarchal culture.

\subsection{Property Right}

In this regard, third important concept is the right of property. In Pakistan, boys are entitled to receive twice as much property to girls as per law. This law is not only applicable to property purposes, rather set a mind-set for masculine culture in which girls are supposed to be subservient to boys irrespective of the nature of relationship (father, brothers younger or older, sons). Therefore, since birth, brothers start expecting to get all shares almost twice than girls, while wrongly generalizing the law of property in their mind. Girls on the other hand would remain passive and ignored while sacrificing their rights and belongings in the perseverance of the laws established by the male dominant society of Pakistan.

\subsection{Beliefs Role in Domestic Life}

It is verified (York, 2011) through various researches that societies where males are taken as superior being in almost all affairs of life, an adversarial environment is created for women to face violence, torture, inequality, discrimination, rape and sexual assault (p.1) and in the culture, where men's masculinity is overly stated and gender roles distinction is highly maintained, domestic violence, psychological, physical and emotional abuses are largely observed and correlated by many researchers until now ( York, 2011). Pakistan is basically comprised of rules and beliefs advocated by males in a male dominated society that encourages the supremacy of males in every field of life; and domestic violence is the ultimate result of such a patriarchic cultures (York, 2011,p.5). In such cultures, male control over women is acceptable and respected and violence against women, to some extent, is tolerated and appreciated (York, 2011,p. 107). Women are thought as inferior to men in such societies and violence against them is considered as less important than violence against men (York,2011,p.107).

It has been verified in a study that sexual stereotypes, especially in Muslim, Latin American, and black African societies, are product of religious and cultural patterns. Such patterns often are transferred from one generation to another through values and beliefs which underlie attitudes, behaviors and norms (Rhoodie, 1989,p. 54). And also proved that, "stereotyping, ignorance, male intransigence and social perceptions (definition of male and female) are at the root of discrimination against women" (Rhoodie, 1989,p. 54).

Therefore, in a culture where traditions and norms are maintained and prioritized on all other things, people follow the religions beliefs blindly, being illiterate and ignorant; how can we save women from discrimination, brutality, injustice and inequality. In Wshington D.C. in 1986, at an international conference on women, it was concluded that traditional beliefs pose one of the greatest challenges to progress for women throughout the world (Rhoodie, 1989,p.457). However, not all traditions are subject to change or replace; some are better ways to live and some are worse. One must understand the sanctity of the law with respect to its usefulness and effectiveness. No law is ever important than preserving the life in danger. Thus if some laws are not worth sustaining, one must leave them immediately for the sake of humanity and goodness.

\subsection{Strategies to remove, replace, and improve old belief system}

There are several strategies that cam be implied in order to change ones mind-set for the better positive interpretation of the world. Usually in the cases of acute or persistent depression, a real identification of the negative beliefs works best to give a relief to the patients. In such therapies, patients are generally made aware of their deep routed or core beliefs, conditional and unconditional beliefs briefly so that they could understand the nature of their problem and could be able to resolve it themselves or with the help of the psychologist or therapist (Moore \& Garland, 2003). However, the following strategies have remained successful among our clients and gained total satisfaction in the rehabilitation process of the victims.

1. For the beliefs based upon argument/condition; change the structure of arguments. There could be several other reasons to do something in a specific manner; find the reason that suits us. For example, in the matter of the tradition, named, 'rukhsati', women can take it lightly. They might perform it as a way to introduce their selves to others; rather than thinking their whole life what it means and in how many ways it can be 
implemented. Then, gradually, it will lose its identity and be replaced by some other tradition- less stressful and more entertaining for all of us.

2. For rigid religious/traditional beliefs, comparative rigid beliefs should be introduced. In this method, one can always search for relevant evidences to support new beliefs and concepts (Moore, Richard G., 2003). Examples of other countries especially the developed ones like UK, USA, Japan, would create an imbalance in the traditional mind-set and provide with new angles to ponder upon. When the victim will see other ways of living, dressing, and enjoying; she would not feel that much prejudice for her present status.

3. For the beliefs based on values, alternative competitive norms should be observed for a pretty longer duration. If it is physically possible, one must change the location, city, or country to live in a new better environment and learn new values to compare, replace the old ones and re-structure the old negative schemas slowly and steadily. It will effect more if one chooses a new advanced and peaceful environment compared to a different but traditional, biased and conservative societal environment (Beck, 2005,p295)

4. For the conflicts in concepts based upon relationships, one must understand other's perspective in the light of reasoning, backgrounds, and convictions. Instead of feeling that others would never accept me if I stand for my rights in a conservative society; women can focus on the thought that others would have to admit the reality that both genders have equal status in terms of rights and responsibilities and no one is superior to other based on gender only. Women need to understand what discriminations is and they should not follow the wrong standards imposed on them by the male members of the society. Arguably, they cannot change others mindset; however they can alter their reaction to others wrong and biased teaching.

5. Therapists may need to use many other strategies over a long period of time to help patients deal with challenging core beliefs: Socratic questioning, changing the comparison procedure, developing new role models, environmental interventions, family involvement, group therapy, dreams and metaphors, imagery techniques, and restructuring the meanings of bitter childhood experiences ( Beck, 2005).

6. It is very important to make the patient understand that the belief they hold are merely a combination of ideas and might not prove a truth to another being, group of persons or society at large. Especially women, who feel unlovable, incompetent, and inferior due to facing severe form of gender discrimination at home since childhood, can modify their core beliefs through working hard on understanding and modifying their coping strategies ( Beck, 2005).

7. When we hold a negative belief for a pretty much long time; our behavior reinforces it and make it stronger day by day. We, unconsciously look at our self and towards our environment with a prejudice mind. We interpret all the information in the light of that core negative belief (beck, 2005).

For example: when a woman in Pakistan feels that she is inferior to men in almost all fields of life; she begins to relate this information being a core belief, with her other beliefs such as:

a. she is less intelligent

b. she is less confident

c. she is less energetic

d. she is less secure

e. she is dependent on men in many fields

f. her duty is to serve others

g. her job is not necessary

h. her first duty is towards her family

i. she should sacrifice first

j. she cannot argue due to her gender

k. she should not walk around like men

l. she could not get a good job and so on.

Thus, the chain of negative thoughts make the core belief that she is inferior to men, stronger and stronger till the time it is very hard to bring a change in it. Beck (2005) has suggested that through analogies, a therapist can help the patient to understand her core negative beliefs. Additionally he recommended making a list of advantages and disadvantages of retaining or replacing core beliefs on daily basis.

\section{Conclusion}

Women are always at risk for depression, anxiety and stresses where discrimination, and inequality between genders 
prevail. In a typical society of Pakistan, many negative beliefs are largely accepted, manipulated and reinforced in the name of religion and traditions. Girls are taken as a burden or responsibility in the hands of parents until they get married, so they no more utilize their full potential for living during their stay in their parent's home. There are many traditions and norms that promote discrimination against women in the patriarchal society of Pakistan. However, the most important and thought provoking are: rukhsati, divorce right and property right. The tradition of 'rukhsati' is very proudly displayed in marriage ceremonies and people do their best effort to give it a new life, to ultimately preserve it for the next generations. However, this tradition is neither in the favor of women folk nor is important for the progress of the country and richness of the culture. Rather it creates a discriminated environment for the women to live in that evokes the feelings of depression, anxiety and low self-esteem.

Second belief that is more of a law by nature is, 'divorce right'. In a patriarchal society of Pakistan, men are very much privileged in almost every field of life including marriage. They can give divorce to their women instantly with no reason; however women need to follow a long, formal, and courageous procedure to get a divorce from their men. Moreover, divorce is taken as a stigma for women that they would have to face later on for the entire life. Therefore they remain under the constant threat of divorce and try to compromise on almost everything in their married life to keep the marriage intact and alive. This situation, by all means, generates anxiety and depressive symptoms among women. More importantly, children suffer a lot due to mother's depressive mood, anxiety and lower level of self esteem. Subsequently, depression, anxiety and lower level of self-esteem, show a great level of co-morbidity with other disorders as well such as conduct problems, ADHD, and suicidal tendencies, and depressive mood (Delfos, 2004,p. 110; Stein, Dan J, 2002; Schwarzer Ralf, 1986).

The third belief about 'property rights' is also worth considering when it comes to the matter of psychological health of women. As per this belief, among siblings, a girl is entitled to one half of the property than a boy. Leaving aside the legal debate about the rights of men and women in specific circumstances; the general observation is that girls feel much insecure and inadequate in almost all fields of life. The implications are not to be ignored. Girls perceive this law as a precursor for their inferior position at home and half right in almost every thing from having a leg piece to buying a car!

It is therefore concluded that women need to get educated on their rights in the light of justice, equality and fairness, to achieve the status they deserve by birth. However, to fulfill this objective, they must understand their exiting belief systems, reshape their perceptual information that cause serious trouble to them, identify other alternatives to replace the old beliefs into new ones, and provide them with new experiences in new environments to satisfy their curiosity and to alter their rigidity within an acceptable time frame.

\section{References}

Beck, Judith S. (2005). Cognitive therapy for challenging problems: what to do when the basics don't work. NY: the Guilford Press.

Delfos, Martine F. (2004). Children and behavioural problems: anxiety, aggression, depression and ADHD. A biopsychological model with guidelines fo diagnostics and treatment. London: Jessica Kingsley Publishers.

Gross Feliks. (1985). Ideologies, goals, and values. UK: greenwood press Westport.

Halstead, J Mark \& Reiss, Michael J. (2003). Values in sex education. London and N.Y. : Routledgefalmer.

Mruk, Christopher J. (2006). Self-Esteem Research, Theory, and Practice towards a positive psychology of self-esteem. NY: Springer publishing company, Inc.

Moore, Richard G \& Garland Anne. (2003). Cognitive therapy for chronic and persistent depression. UK: John Wiley \& Sons Ltd

Moore, Richard G. (2003). Cognitive therapy for chronic and persistent depression. UK: John Wiley \& Sons Ltd.

Rhoodie, Eschel M. (1989). Discrimination against women a global survery of the economic, educational, social, and political status of women. North Carolina: McFarland\&Company,Inc.

Sim, Martha C. \& Martine Stephens. (2011). Living Folklore: An introduction to the study of people and their traditions. Logan, Utah: Utah State University Press.

Stein, Dan J. (2002). Anxiety Disorders comorbid with depression: social anxiety disorder, post-traumatiac stress disorder, generalized anxiety disorder, and obsessive-compulsive disorder. UK: Martin Dunitz Ltd.

Steffenhagen R, A. \& Burns, Jeff D. ( 1987). The social dynamics of self-esteem: theory to therapy. N.Y.: Praeger Publishers.

Schwarzer Ralf (Ed). (1986). Self-related cognitions in anxiety and motivation. London: Lawrence Erlbaum Associates, Publishers.

Walters, Glenn Dn. (2002). Criminal belief systems: an integrated interactive theory of lifestyles. USA : Praeger Publishers

York, Melinda R. (2011). Gender attitudes and violence against women. USA: LFB Scholarly Publishing LLC.

http://www.pakistaniwomen.org/ 